\title{
Changes in Erythrocyte Transmethylation Ability are Predictive Factors for Tumor Prognosis in Prostate Cancer ${ }^{\dagger}$
}

\author{
Anna Blázovics, ${ }^{\mathrm{a}, \mathrm{b}, *}$ Péter Nyirády, ${ }^{\mathrm{c}}$ Gabriella Bekő, ${ }^{\mathrm{d}}$ Edit Székely, ${ }^{\mathrm{b}}$ Ágnes Szilvás, ${ }^{\mathrm{e}}$ \\ Eszter Kovács-Nagy, ${ }^{\mathrm{f}}$ András Horváth, ${ }^{\mathrm{c}}$ Miklós Szúcs, ${ }^{\mathrm{c}}$ Imre Romics, ${ }^{\mathrm{c}}$ and Éva Sárdi ${ }^{\mathrm{f}}$ \\ ${ }^{a}$ Department of Pharmacognosy, Semmelweis University, H-1085 Budapest, Üllöi Rd. 26 \\ ${ }^{\mathrm{b}}$ II. Department of Medicine, Semmelweis University, H-1088 Budapest, Szentkirályi Str. 46 \\ ${ }^{\mathrm{c}}$ Department of Urology, Semmelweis University, 1082 Budapest, Üllöi Rd. 78/b \\ ${ }^{\mathrm{d}}$ Central Laboratory Pest, Semmelweis University, 1083 Budapest, Korányi S. Str. 2/a \\ ${ }^{\mathrm{e}}$ Saint John Hospital, H-1125 Budapest, Diós ditch 1-3 \\ ${ }_{\mathrm{f}}$ Department of Genetic and Plant Breeding, Faculty of Horticultural Science, Corvinus University of Budapest, \\ H-1118 Villányi Rd. 29-43, Budapest, Hungary
}

RECEIVED SEPTEMBER 17, 2010; REVISED NOVEMBER 26, 2010; ACCEPTED DECEMBER 2, 2010

\begin{abstract}
Endogenous transmethylation processes proceed via formaldehyde. Endogenous formaldehyde can be found in special bounded forms in animal tissues. The aim was to find non-invasive methods to help establish an early diagnosis of prostate cancer processes, and to search for a reliable examination repertoire to predict metastasis based on genomic hypomethylation that can be found in tumors. Fifty-eight age-matched patients suffering from prostate cancer and 26 healthy volunteers were enrolled in the study. Biochip technique was applied to quantify serum interleukins and growth factors. OPCL method served to determine mobilized formaldehyde, and fluorometric methods were applied to measure $\mathrm{Zn}$ - and free protoporphyrin concentrations in erythrocytes. Spectrophotometric measurements were carried out to evaluate redox homeostasis in plasma. There were no significant differences in most measured laboratory and immune parameters at different early stages of prostate cancer; at the same time, erythrocyte parameters, especially immobilized formaldehyde determination, were promising. The authors assume that hypomethylation detection in erythrocytes might become a predictive factor in the diagnostic panel in the near future. (doi: 10.5562/cca1748)
\end{abstract}

Keywords: hypomethylation, formaldehyde, protoporphyrin, prostate cancer, redox homeostasis

\section{INTRODUCTION}

A large number of people, mostly around the age of 50, suffer from prostate cancer in the world, and so also in Hungary. In Hungary, 4500 prostate cancer patients and 1400 deaths were registered in 2009. According to a 2008 statistical report, prostate cancer is the second cancer-related cause of death for men in the United States. ${ }^{1}$

Prostate cancer is silent and has no early warning symptoms. Extensive use of serum prostate specific antigen (PSA) testing has been increasingly reported at earlier stages, although false negative or positive diagnoses can occur.

Treating prostate cancer is a major challenge today. In case of localized cancer tissue in a patient in good condition with more than 10 years of life expectancy, radical surgery is the treatment of choice. Bones are the predominant sites of distant metastases caused by prostate cancer. ${ }^{2}$ It is still not possible to determine which patients are at high risk of tumor recurrence after primary local therapy and will not benefit from surgery. No more promising indicators are available to distinguish between surgically curable and oncologically treatable prostate cancers. No optimal factor has so far been found for the prognosis, although several authors maintain that IL-6, IL-10, TNF-alpha and VEGF are increased and IL-2 is decreased in case of the appearance of metastasis in glands and bones. Also, a high titer of C-reactive protein is associated with early tumor recurrence and poor survival in hormone independent tumor occurrences. ${ }^{3-6}$ Increased expression of ID-1 protein regulates the differentiation of osteoblasts and negatively regulates the expression of TNF-beta, which is significantly associated with bone metastasis and shorter survival of prostate cancer patients. ${ }^{7-9}$

\footnotetext{
$\dagger$ This article belongs to the Special Issue Chemistry of Living Systems devoted to the intersection of chemistry with life.

* Author to whom correspondence should be addressed. (E-mail: blaz@drog.sote.hu)
} 
Changes in transmethylation ability and genomic hypomethylation have been verified in both human and animal tumors and experimental evidence suggests their key roles in tumorigenesis. ${ }^{10-12}$

It was earlier clarified that transmethylation processes occur via formaldehyde, mobilized methyl group and not via methyl cation in life systems. ${ }^{13}$

In our previous studies, significant changes were observed in erythrocyte function in colectomized patients suffering from colon cancer. In adult colectomized patients after 5-10 years of colectomy without metastasis, erythrocyte mobilized formaldehyde was significantly lower than in controls. At the same time, protoporphyrin concentration was low in patients without metastasis, when the diagnosis before operation was Dukes C. HbA1c level correlated significantly with induced free radical level and decreased the antioxidant status of erythrocytes. ${ }^{14}$

Explanation of the connection between concentration changes of formaldehyde and protoporphyrin is that arginine (38), methionine (65) and lysine (72) near methionine (80) are methylated and thereby coordinated towards the central iron of heme. Consequently, when the transmethylation activity is normal, the hemoglobin structure is optimal. ${ }^{15}$

Salnikow and Zhitkovich found that genetic and epigenetic mechanisms in metal carcinogenesis and cocarcinogenes depend on nickel, arsenic, and chromium toxicity and that these elements cause hypomethylation. ${ }^{16}$ In previous examinations, we observed that the element status of erythrocytes in patients with prostate cancer was significantly changed compared to controls in cases of Al $(1.90 \pm 1.67 \mathrm{vs}$ $0.537 \pm 0.260)$, $\mathrm{Ni}(0.722 \pm 0.565$ vs $0.265 \pm 0.195)$ and $\mathrm{Pb}(0.309 \pm 0.301$ vs $0.094 \pm 0.053)$. These ion concentrations were significantly high in prostate cancer patients with PSA $>9$ (Ref. 17). At the same time, the erythrocyte protoporphyrin concentration was very high in prostate cancer similarly to cases of gastrointestinal tumors. ${ }^{18}$

Although molecular biological examinations give excellent information about the stages of prostate cancer or metastasis, their clinical applications are very expensive and cannot be widely used.

Since the changes in bounded formaldehyde, $\mathrm{Zn}$ protoporphyrin and free protoporphyrin concentrations of erythrocytes may be very important indices in tumor anemia, we would like to know whether the determination of transmethylation ability via formaldehyde dimedone adduct can be a predictive factor for progression of prostate tumor in clinical applications. Immune reactivity was also examined in searching for correlations between immune parameters, PSA values and transmethylation processes.

\section{MATERIALS AND METHODS}

\section{Materials}

1,1-diphenyl-2-picryl-hydrasyl stable radical and dimedone were obtained from SIGMA (St. Louis), Silica gel 80 F254 precoated chromatoplates were purchased from Merck (Darmstadt) and all other reagents were from Reanal (Budapest). Biochip for the Evidence Biochip Array Analyzer was obtained from Randox (Kearneysville). PSA test was from ABBOTT (Princeton) and CRP kit from Olympus (Corporate Pkwy).

\section{Patients}

The study included a total of 58 patients with prostate cancer, 18 had metastatic prostate cancer and 28 were at an early stage. 12 outpatients had negative and 12 had positive histological findings with questionable PSA values and laboratory parameters. Age range was the same in patient groups and 26 healthy volunteers: $69 \pm 6$ $/ 68 \pm 8$ years.

\section{Methods}

Blood samples were drawn from the antecubital vein by venipuncture into tubes containing $\mathrm{Ca}$ citrate. Plasma, serum and erythrocyte samples were separated by standard methods and stored at $-20{ }^{\circ} \mathrm{C}$ until assayed. Hemoglobin content was adjusted uniformly to $0.01 \mathrm{~g} \mathrm{ml}^{-1}$ for measurements.

Serum routine laboratory parameters were determined with a Hitachi 717 Analyzer, using standard methods (not shown) of Randox. PSA levels were determined using the Abbott MEIA test, and the concentration of CRP was measured with the Olympus immunoturbidimetric test.

Evidence Biochip Array Analyzer (Randox) was employed to quantify serum interleukins: IL-1 alpha and beta, IL-2, IL-4, IL-6, IL-8, IL-10, TNF-alpha, interferon-gamma (IFNG), vascular endothelial growth factor (VEGF), monocyte chemoattractant protein-1 (MCP-1), and epidermal growth factor (EGF) concentrations.

Formaldehyde in the dimedone adduct form (formaldemethone) was identified and determined by the chromarographic method. The samples were treated with dimedone solution $(0.07 \%$ dimedone in methanol) (e.g., $0.7 \mathrm{~cm}^{3}$ sample $/ 0.7 \mathrm{~cm}^{3}$ of dimedone solution). This suspension was centrifuged at $1500 \mathrm{~g}$ for 10 minutes at $4{ }^{\circ} \mathrm{C}$. Clear supernatants were used for chromatographic separation. ${ }^{19}$ Overpressured Layer Chromatographic separation (OPLC developed by OPLC-NIT Co., Ltd., Budapest, Hungary) was carried out on TLC silica gel $60 \mathrm{~F}_{254}$ precoated chromatoplates using a chloroform-methylenechloride mixture (35/65, $v / v)$ for formaldemethone determination. Samples were 
Table 1. Immune parameters of oncological treated prostate cancer patients at different stages and PSA levels

\begin{tabular}{|c|c|c|c|}
\hline \multirow[b]{2}{*}{ Parameters } & \multicolumn{3}{|c|}{ Patient groups } \\
\hline & $\begin{array}{l}\text { healthy controls } \\
\qquad(N=26)\end{array}$ & $\begin{array}{l}\text { early stage } \\
(N=28)\end{array}$ & $\begin{array}{l}\text { metastatic } \\
(N=18)\end{array}$ \\
\hline$\overline{\text { IL-1 alpha } / \mathrm{pg} \mathrm{ml}^{-1}}$ & $0.64 \pm 0.50$ & $0.10 \pm 0.30$ & $0.54 \pm 0.42$ \\
\hline IL-1 beta $/ \mathrm{pg} \mathrm{ml}^{-1}$ & $1.57 \pm 1.3$ & $0.80 \pm 2.20$ & $1.18 \pm 1.60$ \\
\hline $\mathrm{IL}-2 / \mathrm{pg} \mathrm{ml}^{-1}$ & $4.18 \pm 2.80$ & $4.70 \pm 5.60$ & $7.80 \pm 4.4$ \\
\hline $\begin{array}{l}\text { IL-4 / } \mathrm{pg} \mathrm{ml}^{-1} \\
\text { IL-6 / } \mathrm{pg} \mathrm{ml}^{-1}\end{array}$ & $\begin{array}{l}4.56 \pm 1.84 \\
1.51 \pm 1.34\end{array}$ & $\begin{array}{l}2.30 \pm 5.40 \\
1.20 \pm 2.30\end{array}$ & $\begin{array}{l}4.70 \pm 2.05 \\
14.2 \pm 24.20\end{array}$ \\
\hline IL-8 / pg ml ${ }^{-1}$ & $25.21 \pm 16.16$ & $9.10 \pm 16.30$ & $31.20 \pm 87.00$ \\
\hline $\mathrm{IL}-10 / \mathrm{pg} \mathrm{ml}^{-1}$ & $1.08 \pm 0.69$ & $0.20 \pm 0.50$ & $1.54 \pm 1.91$ \\
\hline TNF-alpha / pg ml${ }^{-1}$ & $7.45 \pm 4.23$ & $3.00 \pm 3.60$ & $3.41 \pm 1.65$ \\
\hline $\mathrm{VEGF} / \mathrm{pg} \mathrm{ml}^{-1}$ & $190 \pm 150$ & $183 \pm 94$ & $272 \pm 116$ \\
\hline $\mathrm{IFNG} / \mathrm{pg} \mathrm{ml}^{-1}$ & $1.78 \pm 1.41$ & $0.8 \pm 1.50$ & $4.28 \pm 4.21$ \\
\hline $\mathrm{MCP} 1 / \mathrm{pg} \mathrm{ml}^{-1}$ & $346 \pm 158$ & $306 \pm 93$ & $347 \pm 171$ \\
\hline $\mathrm{EGF}^{*} / \mathrm{pg} \mathrm{ml}^{-1}$ & $212 \pm 81$ & $66.8 \pm 58.3$ & $59.3 \pm 40.4$ \\
\hline $\mathrm{CRP} / \mathrm{pg} \mathrm{ml}^{-1}$ & $<5$ & $5.6 \pm 12.8$ & $14.4 \pm 24.9$ \\
\hline $\mathrm{PSA} / \mathrm{pg} \mathrm{ml}^{-1}$ & $<2$ & $10.66 \pm 7.79^{*}$ & $93 \pm 120^{* *}$ \\
\hline
\end{tabular}

Significance $(\mathrm{p}<0.05)$ : control $v_{S}^{*} ; * v_{S} * *$.

applied with a NANOMAT sample applicator (CAMAG Co., Muttenz, Switzerland). Calibration curves were prepared using an authentic substance. For densitometric determination, a Shimadzu CS-930 TLC/HPTLC scanner (Shimadzu Co., Kyoto, Japan) $\lambda=265 \mathrm{~nm}$ was used.

Erythrocyte protoporphyrin IX and Zn-protoporphyrin were measured by the fluorometric method using a Jasco FP 6300 type fluorometer (Jasco Co, Japan). Simple micro-method was adapted for purification of protoporphyrin by Chisolm and coworkers (1975). ${ }^{20}$ Excitation wavelength was $405 \mathrm{~nm}$ and that of emission $610 \mathrm{~nm}$.

The reducing power of the sample was determined at $700 \mathrm{~nm}$ according to Oyaizu, based on the chemical reaction $\mathrm{Fe}(\mathrm{III}) \rightarrow \mathrm{Fe}(\mathrm{II})$. Increased absorbance indicated increased reducing power, which was expressed as ascorbic acid equivalent ( $\mathrm{mmol} / \mathrm{l} \mathrm{eqAS}){ }^{21}$

The hydrogen-donating ability of the sample was estimated in the presence of 1,1-diphenyl-2-picrylhydrazyl radical according to Hatano et al. ${ }^{22}$

Free SH-groups were determined by the Sedlack method, based on the Ellmann reaction (1985). ${ }^{23}$ All spectrophotometic methods were carried out with a Jasco V 550 spectrophotometer (Jasco Co., Japan).

One-way ANOVA statistical analysis was applied to evaluate the significance between patient groups.

This study was approved by the Regional and Institutional Committee of Science and Research Ethics, Semmelweis University, Permission Number TUKEB $127 / 2006$.

\section{RESULTS AND DISCUSSION}

Since laboratory diagnosis of prostate cancer is difficult at an early stage and prostate specific antigen can remain in normal range or be falsely positive, the generally used laboratory parameters do not signal the appearance of the disease. IL-1 alpha, -beta, IL-2, IL-4, IL-6, IL-8, IL-10, TNF-alpha, interferon-gamma, vascular endothelial growth factor, monocyte chemoattractant protein-1 and epidermal growth factor concentrations were determined by the biochip technique with an Evidence Biochip Array Analyzer to establish the progression of tumor process. Table 1 does not show any significant differences in most parameters between study groups and controls. Levels of cytokines and growth factors were low at the early stage of prostate cancer. We found concentrations of IL-1 alpha and -beta, IL-10, IFNG (60-80\%) below the measurement range. Serum PSA correlated with serum IL-6 $(r=0.78)$ but the other markers did not. CRP value was under $5 \mathrm{mg} / 1$ in all samples and was not related to the measured parameters. When low concentrations of the above mentioned parameters are found in the sera of patients with prostate cancer, we can suppose an early stage of cancer. Our results show that measurements of cytokines and growth factors did not help establish an early diagnosis of prostate cancer. It is an interesting fact that the concentrations of cytokines and growth factors are significantly lower in old men (age range 60-75 years) than in younger ones (data not published). 
Table 2. Plasma redox parameters of oncological treated cancer patients at different stages

\begin{tabular}{lccc}
\hline Patients & $\begin{array}{c}\text { Plasma free SH-group } \\
(\mathrm{mmol} / \mathrm{l})\end{array}$ & $\begin{array}{c}\text { Reducing power } \\
(\mathrm{mmol} / \mathrm{l} \mathrm{eqAS})\end{array}$ & $\begin{array}{c}\text { H-donating ability } \\
\text { (inhibition \%) }\end{array}$ \\
\hline Healthy control $(N=14)$ & $0.535 \pm 0.052$ & $1.320 \pm 0.249$ & $53.95 \pm 3.42$ \\
Prostate tumor (histology -$)(N=12)$ & $0.671 \pm 0.161^{*}$ & $1.358 \pm 0.230$ & $60.26 \pm 5.082$ \\
Prostate tumor (histology +$)(N=12)$ & $0.667 \pm 0.086^{*}$ & $1.249 \pm 0.226$ & $54.83 \pm 9.23$ \\
Prostate tumor (metastatic) $(N=18)$ & $0.487 \pm 0.063^{* *}$ & $1.368 \pm 0.207$ & $50.41 \pm 7.91$ \\
\hline
\end{tabular}

Significance $(\mathrm{p}<0.05) * v s * *$.

Table 3. Erythrocyte parameters of oncological treated cancer patients at different stages

\begin{tabular}{|c|c|c|c|c|}
\hline Patients & $\begin{array}{l}\text { Zn-protoporhyrin } \\
\text { (nmol/1 ery) }\end{array}$ & $\begin{array}{l}\text { Free- protoporhyrin } \\
\text { (nmol/1 ery) }\end{array}$ & $\begin{array}{l}\text { Erythrocyte formaldehyde } \\
\qquad(\mu \mathrm{mol} / \mathrm{ml})\end{array}$ & $\begin{array}{l}\text { PSA } \\
(\mathrm{ng} / \mathrm{ml})\end{array}$ \\
\hline Healthy control $(N=14)$ & nd & nd & $1.52 \times 10^{-2} \pm 1.25 \times 10^{-3}$ & nv \\
\hline Prostate tumor (histology -$)(N=10)$ & $1282 \pm 513^{*}$ & $325 \pm 50^{*}$ & $1.06 \times 10^{-2} * \pm 1.44 \times 10^{-3}$ & $9.66 \pm 5.28^{*}$ \\
\hline Prostate tumor (histology +$)(N=30)$ & $1043 \pm 372 *$ & $582 \pm 782 *$ & $7.830 \times 10^{-3 * *} \pm 2.56 \times 10^{-3}$ & $13.68 \pm 21.91 *$ \\
\hline Prostate tumor (metastatic) $(N=18)$ & $1303 \pm 3601^{*}$ & $300 \pm 64^{*}$ & $1.02 \times 10^{-3 * * *} \pm 2.73 \times 10^{-4}$ & $93 \pm 120^{* *}$ \\
\hline
\end{tabular}

(a) nd - not detected.

(b) $\mathrm{nv}$ - value is in normal range (normal value of PSA is $0.01-4.00 \mathrm{ng} / \mathrm{ml}$ ).

Significance: control $v s * ; * * * * * ; * v s * * ; * * v s * * *$.

When we examined the plasma redox parameters of patients suffering from prostate cancer and healthy controls, we observed only moderate alterations. These data did not help establish an early diagnosis and follow cancer progression unambiguously contrasted to inflammatory bowel diseases, where data indicate moderate and serious forms of diseases (Table 2). ${ }^{24}$

At the same time, erythrocyte parameters, Znprotoporhyrin, free protoporhyrin and bounded $\mathrm{HCHO}$ in sensitized dimedone reaction, showed enormous differences compared to healthy controls not only in taxane-treated metastatic but also in histologically negative and positive patients when cancer was first observed. In particular, bounded formaldehyde in erythrocytes showed alterations compared to healthy controls and signaled moderate transmethylation ability at an early stage. Significant differences in this parameter were found between groups. These data showed that transmethylation ability was changed in the course of cancer progression (Table 3).

Early research has already drawn attention to the alterations in DNA methylation, which play an important role in neoplasia. ${ }^{25}$ DNA hypomethylation leads to elevated mutation rates. ${ }^{26}$ Nowadays, many review publications reveal that the most studied mechanisms by epigenetics are DNA methylation and histone medications, stable and reversible alterations to the genome that affect gene expression and genome function. The nature and role of the mechanisms of promoter hypermethylation during carcinogenesis have been studied worldwide; however, the mechanism behind one of the earliest epigenetic observations in cancer, genome-wide hypome- thylation, remains unclear. ${ }^{27}$ Tumor hypermethylation predicts poor prognosis in patients with earlier stages of prostate cancer, and is commonly found in the plasma DNA of patients with castration-resistant prostate cancer. $^{28,29}$ Extensive molecular biological examinations help us more and more to understand the mechanism of methylation steps, biochemical pathways, key enzyme functions and, recently, to apply targeted therapy., ${ }^{30,31}$ Researchers are now searching for natural bioactive agents, to modify DNA methylation, such as curcumin, which has a potent DNA hypomethylation property. ${ }^{32}$

On the basis of our earlier and present studies, hypomethylation seems to be a condition of the system, which can be improved with methyl donating molecules from food ingredients, such as different $\mathrm{N}-, \mathrm{S}-$, and O- methylated compounds. The exact mechanisms are not known, but the effectiveness can be checked by laboratory parameters and improved transmethylation ability of erythrocytes in cancer patients. ${ }^{18,33}$

\section{CONCLUSION}

To conclude, we can say that the determination of transmethylation ability in erythrocytes and plasma PSA levels may constitute a new methodical approach to detecting prostate cancer at an early stage, follow its progression and apply the most suitable therapy. The authors suppose that exhaustion of the system methyl donor pool causes hypomethylation in DNA and histone. This fact is reflected in erythrocyte function in cancer processes. The found connections can be in con- 
cord with serious tumor anemia in metastatic carcinoma. Although the preliminary results presented in this paper are very promising, further studies on a larger number of patients have to be carried out to assess the safety and reliability of this method.

\section{ABBREVIATIONS}

$\mathrm{CRP}, \mathrm{C}$ reactive protein; $\mathrm{EGF}$, epidermal growth factor; $\mathrm{HbA1c}$, glycated hemoglobin $\mathrm{HCHO}$, formaldehyde; ID1, DNA-binding protein inhibitor ID-1 (inhibitor of differentiation-1); IFNG, interferon-gamma; IL-1 alpha/beta, IL-2, IL-4, IL-6, IL-8, IL-10, interleukins; OPLC, overpressure layer chromatography; PSA, prostate-specific antigen; TNF-alpha, tumor necrosis factor-alpha.

Acknowledgements. This work was supported by the Health Sciences Scientific Committee ETT 354/2006, ETT 012/02, ETT 02/02. The authors express their thanks to Mrs. Sarolta Bárkovits, Mrs. Edina Pintér and Mrs. Judit Sablyán for their excellent technical assistance.

\section{REFERENCES}

1. A. Jemal, R. Siegel, E. Ward, Y. Hao, J. Xu, T. Murray, and M. Thun, CA Cancer J. Clin. 58 (2008) 71-96.

2. R. Coleman, Clin. Cancer Res. 12 (2006) 6243s-6249s

3. M. Bălăşoiu, A, Turculeanu, C, Avrămescu, V. Comănescu, C. Simionescu, and L. Mogoantă, Rom. J. Morphol. Embryol. 46 (2005) 179-182.

4. B. Thomson, G. Mundy, and T. Chambers, J. Immunol. 138 (1987) 775-779.

5. M. Ling, X. Wang, X. Ouyang, T. Lee, T. Fan, K. Xu, S. Tsao, and Y. Wong, Oncogene 21 (2002) 8498-8505.

6. P. A. McArdle, D. C. McMillan, N. Sattar, A. M. Wallace, and M. A. Underwood, Brit. J. Cancer 91 (2004) 1755-1757.

7. H. F. Yuen, Y. T. Chiu, K. K. Chan, Y. P. Chan, C. W. Chua, C. M. McCrudden, K. H. Tang, M. El-Tanani, Y. C. Wong, X. Wang, and K.W. Chan, Transl. Ther. Brit. J. Cancer 102 (2010) 332-341.

8. S. Forootan, Y. Wong, A. Dodson, X. Wang, K. Lin, P. Smith, C. Foster, and Y. Ke. Hum. Pathol. 38 (2007) 1321-1329.

9. H. Yuen, C. Chua, Y. Chan, Y. Wong, X. Wang, and K. Chan, Mod. Pathol. 19 (2006) 931-941.

10. R. Guerrero-Preston, R. M. Santella, A. Blanco, M. Desai, M. Berdasco, and M. Fraga, Epigenetics 2 (2007) 223-226.

11. R. E. Watson, G. M. Curtin, D. J. Doolittle, and J. I. Goodman, Toxicol. Sci. 75 (2003) 289-299.
12. D. F. Calvisi, S. Ladu, A. Gorden, M. Farina, J. S. Lee, E. A. Conner, I. Schroeder, V. M. Factor, and S. S. Thorgeirsson, J. Clin. Invest. 117 (2007) 2713-2722.

13. Z. Huszti and E. Tyihák, FEBS Lett. 209 (1986) 362-366.

14. A. Blázovics, Á. Szilvás, Gy. Székely, E. Tordai, E. Székely, G. Czabai, Zs. Pallai, and É. Sárdi, Important bioactive molecules of erythrocytes in colorectal cancer patients after colectomy. Open Med. Chem. J. 2 (2008) 6-10.

15. L. Stryeer, Biochemistry $3^{\text {rd }}$ In: V. H. Freeman and Co. (Eds.), New York, 1988. p. 614, 678.

16. K. Salnikow and A. Zhitkovich, Chem. Res. Toxicol. 21 (2008) 28-44.

17. P. Nyirády, A. Blázovics, I. Romics, Z. May, E. Székely, G. Bekő, and K. Szentmihályi, Vol. 3. Deficiency or excess of trace elements in the environment as a risk of health, Eds. Szilágyi M. and Szentmihályi K. Hungarian Academy of Sciences, TEFC. Budapest, 2009. p. 26-30.

18. P. Nyirády, É. Sárdi, G. Bekő, M. Szücs, A. Horváth, E. Székely, K. Szentmihályi, I. Romics, and A. Blázovics, Orv. Hetil. 37 (2010) 1495-1503.

19. É. Sárdi, and E. Tyihák, Biomed. Chromatogr. 8 (1994) 313-314.

20. J. J. Chisolm and D. H. Jr. Brown, Clin. Chem. 21 (1975) 1669-1682.

21. M. Oyaizu, Jpn. J. Nutr. 44 (1986) 307-315.

22. T. Hatano, H. Kagawa, T. Yasuhara, and T. Okuda, Chem. Pharm. Bull. 36 (1988) 2090-2097.

23. J. Sedlak, and R. H. Lindsay, Anal. Biochem. 25 (1968)192-205.

24. A. Blázovics, Á. Kovács, A. Lugasi, K. Hagymási, L. Bíró, and J. Fehér, Clin Chem. 45 (1999) 895-896.

25. S. B. Baylin, J. G. Herman, J. R. Graff, P. M. Vertino, and J. P. Issa, Adv. Cancer. Res. 72 (1998) 141-196.

26. R. Z. Chen, U. Pettersson, C. Beard, L. Jackson-Grusby, and R. Jaenisch, Nature 395 (1998) 89-93.

27. L. Wild and J. M. Flanagan, Biochim. Biophys. Acta 1806 (2010) 50-57.

28. E. Rosenbaum, M. O. Hoque, Y. Cohen, M. Zahurak, M. A. Eisenberger, J. I. Epstein, A. W. Partin, and D. Sidransky, Clin. Cancer Res. 11 (2005) 8321-8325.

29. P. J. Bastian, G. S. Palapattu, S. Yegnasubramanian, C. G. Rogers, X. Lin, L. A. Mangold, B. J. Trock, M. A. Eisenberg, A. W. Partin, and W. G. Nelson, J. Urol. 179 (2008) 529-534.

30. I. P. Pogribny, V. P. Tryndyak, A. Boureiko, S. Melnyk, T. V. Bagnyukova, B. Montgomery, and I. Rusyn, Mutat. Res. 644 (2008) 17-23.

31. A. S. Wilson, B. E. Power, and P. L. Molloy, Biochim. Biophys. Acta 1775 (2007) 138-162.

32. Z. Liu, Z. Xie, W. Jones, R. E. Pavlovicz, S. Liu, J. Yu, P-k. Li, J. Lin, J. R. Fuchs, G. Marcucci, C. Li, and K. K. Chan, Bioorg. Med. Chem. Lett. 19 (2009) 706-709.

33. L. Váli, É. Stefanovits-Bányai, K. Szentmihályi, H. Fébel, É. Sárdi, A. Lugasi, I. Kocsis, and A. Blázovics, Nutrition 23 (2007) 172-178. 